\title{
EDUCAÇÃO INCLUSIVA: formação e capacitação dos profissionais ao deparar com a inclusão no ensino regular
}

\author{
Marieli Lopes ALVES ${ }^{1}$ \\ Gleicione Aparecida Dias Bagne de SOUZA ${ }^{2}$
}

Recebido em: 05/10/2015 - Aprovado em: 02/12/2015 - Disponibilizado em: 18/01/2016

\begin{abstract}
Resumo:
O Interesse em discutir este tema decorre de vários motivos, todos eles apontando para a necessidade de tomar iniciativas que visem à construção de novas metodologias para uma educação inclusiva. As reflexões apresentadas produziram-se a partir da análise da compreensão que os profissionais têm sobre sua formação e as práticas pedagógicas de ensino. O Objetivo é apresentar os principais fundamentos da Educação Inclusiva, enfocando o papel dos profissionais e sua formação no processo educacional, afim de sensibilizar a todos aqueles que se interessam em compreender, aceitar e lidar com a diversidade no contexto humano, educacional e social.
\end{abstract}

Palavras-Chave: Educação Inclusiva. Formação. Profissionais. Práticas pedagógicas.

\section{INCLUSIVE EDUCATION: education and training of health professionals when confronted with the inclusion in regular education}

\begin{abstract}
:
The interest in discussing this topic due to several reasons, all pointing to the need to take initiatives aimed at the construction of new methodologies for inclusive education. The reflections presented here were produced from the analysis of the understanding that professionals have about your training and the pedagogical practices of teaching. The goal is to present the main foundations of Inclusive Education, focusing on the role of professionals and their training in the educational process in order to reach out to those interested in understanding, accepting and dealing with diversity in the human context, social and educational. As a personal goal, I intend to finish this work to transform my ideas and certainly not my way of acting and teaching people with special needs. As a psychologist, reflecting and reconstructing concepts about disability, learning, inclusion, and my training.
\end{abstract}

Keywords: Inclusive Education. Training. Professionals. Pedagogical practices.

\footnotetext{
${ }^{1}$ Psicopedagoga Institucional e Clínica pelo Centro Universitário do Sul de Minas.

2 Doutora em Educação pela Universidade do Minho - Portugal e convalidado pela Universidade de São Paulo. E-mail: gleici@unincor.edu.br 


\section{1 - INTRODUÇÃO}

Iniciaremos o artigo conhecendo um pouco sobre o significado de inclusão. Segundo o dicionário Aurélio:

Inclusão é ato ou efeito de incluir, isto é, de compreender (entender alguém, aceitá-lo como é), abranger (conter em si, mas também, apreender, perceber, entender, alcançar, atingir); em estudos da linguagem, inclusivo se diz da $1^{\circ}$ pessoa do plural, que inclui o falante e o ouvinte. (1999, p. 982)

A inclusão, nada mais é que um movimento mundial de lutas das pessoas com deficiências e seus familiares, na busca de seus direitos e lugar nas diversas esferas da sociedade. No âmbito da educação, viu-se a necessidade e o desafio de oferecer um ensino de qualidade para todos, inclusive aos que possuem deficiências ou outras necessidades especiais, de serem inseridos no sistema de ensino regular.

Ao falar de inclusão é necessário repensar no sentido e significado deste tema.

A educação Inclusiva significa um novo modelo de escola em que é possível o acesso e a permanência de todos os alunos, e onde os mecanismos de seleção e discriminação, até então utilizados, são substituídos por procedimentos de identificação e remoção das barreiras para aprendizagem. (GLAT, 2007, p. 20).

O Processo de inclusão social das pessoas com deficiência, iniciou-se nos anos
80, em outros países. A Política Nacional da Educação Especial e a Lei de Diretrizes e Bases da Educação definiram e alavancaram o processo no Brasil.

Para garantir o avanço no processo de inclusão escolar, faz-se necessário a definição de uma política de formação de professores e sua implantação apoiando-se na necessidade de garantir o acesso aos novos conhecimentos e produções e a reflexão sobre prática profissional dos docentes.

A inclusão é possível e necessária, tanto para o aluno como para professor ou para qualquer outro profissional. Mas é necessário destacar que além de investimento na sua formação e especialização, o mesmo tenha consigo força de vontade e dedicação, pois é no ambiente da escola que o profissional tem a sua função mais efetiva e o papel fundamental de mediador da aprendizagem e de ajuda mútua.

O professor é como principal veículo de informação, pois a ele compete ensinar e ingressar o indivíduo na cultura letrada, é sempre visto na sociedade como responsável por vários fracassos e também vitórias, pois o grande desafio desses profissionais da educação diz respeito á dinâmica do cotidiano na sala de aula, além de atender tantos educandos que demandam sua atenção, precisa também atender alunos que apresentam peculiaridades e dificuldades acentuadas no processo de aprendizagem. 
Sobre outros profissionais capazes de atender as necessidades para uma inclusão, referimos a uma equipe multidisciplinar contendo: professores, psicólogo, fisioterapeuta, terapeuta ocupacional, fonoaudiólogo, psicopedagogo e entre outros. Desta forma, contendo uma equipe capacitada, o processo de inclusão contará com ajudas necessárias para atender as necessidades de cada aluno.

O processo educacional, especialmente no ensino regular, passa hoje por um desencontro de ações, uma crise de comprometimento com as Dificuldades de Aprendizagem que se apresentam em alguns alunos. Essa falta de comprometimento acontece tanto por parte da escola como por parte de muitos pais, o que resulta em duas situações peculiares: de um lado encontra-se o professor em uma situação de conflito, porque em alguns casos não recebeu uma formação específica para trabalhar com esses alunos. E de outro lado temos o próprio aluno que se sente fracassado e excluído de um sistema de ensino concebido apenas para crianças que tem um "bom" ritmo de aprendizagem. Essa problemática de não se saber ao certo como proceder diante dessas crianças com dificuldades, torna a escola simplesmente reprodutora do problema, incapaz de auxiliar nesses casos, em virtude de sua forma de organização.

O processo de inclusão escolar está atrelado ao desenvolvimento do conceito de adaptações curriculares. Conforme estabelece as diretrizes das políticas nacionais de Educação Especial, norteadas pela LDB 9394/96 e outros documentos legais do MEC enfatizam a importância das práticas inclusivas no cotidiano da escola e da inserção, no projeto político-pedagógico na mesma, de adaptações curriculares.

Quanto maior a dificuldade do aluno, mais significativas serão as adequações no currículo para atender seus diferentes níveis de exigência. Isto é, maior a necessidade de se adotarem medidas extraordinárias de ajustes ou modificações que se efetuem nos objetivos, conteúdos, metodologias e atividades de ensino-aprendizagem e nos critérios de avaliação para atender a tal diversidade.

Feitas estas considerações a respeito da Educação Inclusiva, o presente trabalho propõe uma reflexão, ao pensar e repensar a importância da formação dos profissionais e de suas práticas pedagógicas no ensino regular.

O desenvolvimento deste trabalho baseia-se em pesquisas bibliográficas procura explicar um problema a partir de referencias teóricas publicadas, buscando conhecer e analisar as contribuições culturais. 


\section{2 - INCLUSÃO}

\section{1- Um pouco da história}

Superar discriminações de etnias, de gêneros, de preferência sexual, de normalidade, de classes sociais entre outras, é o grande desafio do movimento de inclusão perante a sociedade.

No mundo contemporâneo, a convivência humana com a diversidade passou a ser um problema. A partir de ideias sociais, a sociedade foi moldando e acreditouse na existência de um saber universal, a ser seguido por todos.

Juntamente com este tipo de padronização vieram pré-conceitos, que gradativamente promoveram a discriminação e o tratamento desigual entre as pessoas. $\mathrm{O}$ fato acabou levando á exclusão, já que os sujeitos que se desviavam dos valores padronizados pela sociedade eram excluídos.

Finalmente em 1.994 com a Declaração de Salamanca (UNESCO), a concepção de educação inclusiva substituiu definitivamente o conceito de educação especial, ampliando o conceito e defendendo a necessidade de inclusão dos alunos especiais no sistema regular de ensino.

Atualmente a educação inclusiva é a política educacional oficial do país, amparada pela legislação em vigor e convertida em diretrizes para a educação básica dos sistemas federais, estaduais e municipais de ensino.

\section{2- Princípios da educação inclusiva}

A educação inclusiva traz uma ideia ampliada do processo de ensino e de aprendizagem. Mostrando que todos podem aprender se suas diferenças forem respeitadas e trabalhadas. A escola torna-se um lugar propício para a construção de novos referenciais, pois é na convivência com seus pares, que não apresentam as mesmas particularidades, que eles podem aprender novas noções e habilidade.

O estabelecimento da Educação
Inclusiva comorítica
educacional do país- tanto para o
ensino público quanto privado-
coloca em questionamento os
pressupostos que
consubstanciavam a escola como,
tradicionalmente, a conhecermos.
Esta agora para a ser, por
princípio, uma instituição social a
que todos tem direito de acesso e
permanência, sendo sua
responsabilidade, portanto,
oferecer um ensino de qualidade
para todos os alunos. (GLAT,
2007, p.29). O princípio da inclusão visa garantir o acesso e a permanência de todos, a fim de se impedir a segregação e o isolamento como fora praticado ao longo dos tempos. Envolve um repensar da política de ensino e de aprendizagem.

Sobre a importância que a Educação Inclusiva nos traz, destacam-se aqui alguns dos seus princípios.

- Cada criança tem o direito fundamental á educação e deve 
ter a oportunidade de conseguir e manter um nível aceitável de aprendizagem.

- Cada criança tem características, interesses, capacidades e necessidades de aprendizagem que lhe são próprios.

- Os sistemas educativos devem ser projetados e os programas aplicados de modo que se tenham em vista toda gama dessas diferentes características e necessidades.

- As crianças e jovens com necessidades educacionais especiais devem ter acesso ás escolas regulares, que deverão incluí-las numa pedagogia centralizada na criança, capaz de entender a essas necessidades.

- As escolas regulares, seguindo esta orientação inclusiva, constituem os meios mais capazes para combater as atitudes discriminatórias, criando comunidades abertas e solidárias, construindo uma sociedade inclusiva e atingindo a educação para todos; além disso, proporcionam uma educação adequada à maioria das crianças e promovem a eficiência, numa ótima relação custo qualidade, de todo o sistema educativo.

(DECLARAÇÃO

DE SALAMANCA, 1994 p.1)

A Educação Inclusiva pressupõe que a sociedade e as instituições é que são opressivas e discriminatórias, portanto, estas precisam remover os obstáculos existentes á participação das pessoas com deficiências. Faz-se necessário a reestruturação das escolas, baseando-se em diretrizes inclusivas, requerendo a integração entre as necessidades e as alterações dos sistemas escolares.

Alguns níveis podem ser apontados nos casos em que essas mudanças deverão ocorrer no âmbito educacional.

É necessário haver uma maior flexibilidade para a construção de propostas pedagógicas e de organização escolar; A inclusão implica que os professores, tem o direito de receber preparação apropriada na formação inicial em educação e no desenvolvimento profissional contínuo; e a inclusão indica a necessidade da alteração da estrutura física das escolas.

Assim sendo, a Educação Inclusiva, propõe uma mudança na educação que deverá levar em conta o currículo, os processos avaliativos, a pedagogia, e as práticas docentes. E não pode deixar de considerar as oportunidades de cultura, esporte, lazer e 
recreação, que deverão compor o projeto pedagógico da escola.

\section{3- EQUIPE MULTIDISCIPLINAR.}

Uma equipe multidisciplinar pode ser definida como:

Um grupo de indivíduos com contributos distintos, com uma metodologia compartilhada frente a um objetivo comum, cada membro da equipe assume claramente as suas próprias funções, assim como os interesses comuns do coletivo e todos os membros compartilham as suas responsabilidades e seus resultados (ZURRO; FERREROX; BAS, 1991, p. 29).

Dentro dessa perspectiva a equipe multidisciplinar é integrada por diversos profissionais das áreas diferentes, com o objetivo comum, no caso da educação especial,voltados para as necessidades do aluno, cada um dentro de sua área trazendo contribuições para a resolução das necessidades de cada educando.

É encontrado esboços de equipes multidisciplinares em que os membros participantes atuam de forma individual, cada um na sua área, e as intervenções acontecem de forma isolada não havendo uma articulação e troca de informações entre os profissionais. Predominam ainda lógicas individualistas, isolando saberes, separando o tempo de formação da sua ação, valorizando a teoria, e separando esta da sua prática, assume uma peculiaridade destacada na forma social de exercer o trabalho.

É esta constatação que Huberman (1973, apud GARCIA,1994) explicita quando afirma que: "na educação os grupos interdisciplinares de especialistas ainda não encontraram linguagem comum, métodos de pesquisa comuns e modos comuns de percepção que lhes permitam convergir sobre os problemas da educação".

Quando se trata de equipe multidisciplinar não pode deixar de falar em interdisciplinaridade.

Segundo Mendes (1995) a interdisciplinaridade implica no plano prático operacional em que se estabelece mecanismos e estratégias de efetivação de um diálogo solidário no trabalho científico, tanto na pratica da pesquisa como na do ensino e da prestação de serviços.

A interdisciplinaridade é fundamentada num regime de cooperação, possibilitando diálogo entre as diversas áreas, o que leva a uma interação, condição indispensável para a efetivação do trabalho em equipe.

É necessário que os profissionais tenham a capacidade de trabalharem numa visão de totalidade, sem anular o seu saber individual diante do saber coletivo.

$\mathrm{Na}$ prática, a interdisciplinaridade cria estratégias enriquecedoras para a ação 
profissional produzindo uma competência que dificilmente o indivíduo sozinho teria.

$\mathrm{Na}$ área da educação, a presença de diferentes profissionais, atuando em equipes, em vez de tornar a escola mais eficaz, tem também mostrado problemas de funcionamento que tem contribuído para a fragilização dos professores e de outros profissionais.

Se, como vimos, parece
problemática a intervenção desses
profissionais, e se a sua
contribuição hoje é uma
evidência, então, a questão talvez
se situe na forma como a escola
terá que se organizar e como
deverá estruturar para a
participação dos diferentes
profissionais que com ela
colaboram.(GARCIA,1994, p.12).

As equipes multidisciplinares podem ser um dos lugares de produção de sentidos novos para o trabalho educativo, tanto no ensino regular como nas escolas de educação.

Ninguém nasce competente, isso ocorre por meio da busca do saber conhecendo novas teorias, técnicas e as colocando em prática com comprometimento e responsabilidade junto ao trabalho.

A questão do saber está diretamente relacionada ao nosso cotidiano que nos leva a buscar novos conhecimentos e a repensar nossas atitudes como profissionais.

O trabalho multiprofissional implica em responsabilidade, respeito aos colegas, porque o profissional realiza o seu trabalho voltado para o grupo de forma que a equipe cresça, principalmente na qualidade dos serviços prestados.

A equipe pode ser exemplificada como um corpo onde os membros devem funcionar integrados para o bom andamento do todo.

\begin{abstract}
Mais do que participar em atividades de inovação e mudança é necessário encontrar sentidos através de entendimentos e vontades. É o reencontro com o sentido de pertença quando ganha vulto a pergunta, quem sou eu? Mais do que ser professor, médico, psicólogo, assistente social ou fonoaudiólogo, é decisiva a atribuição de significados que cada um coloca na sua participação no processo educativo (GARCIA, 1994, p. $55)$.
\end{abstract}

\section{4 - O TRABALHO NA DIVERSIDADE}

Para falar do trabalho na diversidade, antes de qualquer coisa é importante que se faça um exame a cerca das diferenças sob visão econômica, política e social.

Ao se adentrar em uma escola, pode-se perceber rapidamente o quão é heterogêneo a classe do alunado. Diversas são as características, sejam elas corporais, comportamentais, experiências de vida, atitudes, estilos de aprendizagem, dentre outras. Quanto ao espaço físico, constatamos que as condições estruturais quase sempre não são adequadas para atender á diversidade de alunos. E também tem os professores, que se 
queixam constantemente dessas condições, do tamanho das turmas e das inúmeras dificuldades que surgem para atender ás diferenças individuais de seus alunos.

Diante deste cenário, Elder Carvalho

faz a seguinte observação sobre os educadores:

Muitos desanimam e desistem (de si mesmo, eu diria). Mas felizmente há outros que decidem lutar, conscientes da importância do papel que desempenham e que, além de pedagógico, é também político e social. Estes reconhecendo as diferenças existentes entre os alunos, não ficam indiferentes a elas nem caem na cilada dos "diferentes mais iguais". Procura rever sua prática pedagógica em sala de aula, buscando ensinar a toda turma, tornando a escola um espaço de aprendizagem e de participação de todos, com todos e para toda vida. Um espaço inclusivo, de fato. Um espaço onde todos são bem vindos, reconhecidos em suas diferenças e valorizados como sujeitos de potencialidades, com direito de aprender em benefício da melhoria da qualidade de suas vidas e para se tornarem cidadãos contributivos na sociedade. (2008, p.63)

O fazer pedagógico dos educadores é de suma importância para que se tenha de fato uma educação inclusiva.

Para que isso ocorra deve-se ter um processo de inclusão educacional, porém para que o mesmo ocorra, fica evidenciado que algumas mudanças são necessárias. Características como dinamismo, flexibilidade e temporalidade são essenciais.
Os profissionais devem apoiar-se mutuamente ajudando uns aos outros e de desenvolverem, promovendo o reconhecimento do potencial humano diante da diversidade.

\section{5 - CONCLUSÃO}

A proposta deste artigo foi refletir os principais fundamentos da Educação Inclusiva, enfocando o papel do professor e de uma equipe multidisciplinar, suas competências e as estratégias para se trabalhar com os alunos portadores de necessidades educacionais especiais.

Uma proposta de Educação Inclusiva parte da premissa que, independente da estrutura educacional que lhe seja oferecida, todos os alunos têm direito de frequentar as mesmas escolas e aprender, inclusive aqueles com necessidades educacionais especiais, cabendo á escola proporcionar experiências significativas, que lhes possibilitem compartilhar dos conhecimentos culturais socialmente construídos.

Pode-se dizer que a Educação Inclusiva é a questão mais atual em Educação Especial, por colocar o desafio de participar do contexto da escola comum. A inclusão se faz em processo e, como tal, seu entendimento deve ser compartilhado por todos os envolvidos que, por sua vez, assumirão papel de atores nesta construção. 
Garantida hoje pela legislação em nível federal, estadual e municipal, cabe os órgãos governamentais e as instituições publicas e privadas implementar a Educação Inclusiva de forma satisfatória.

Quanto aos educadores e demais profissionais, foi visto durante todo este artigo que é um grande desafio desenvolver estratégias de ensino- aprendizagem que atendam a diversidade do alunado que freqüenta as escolas atuais. Há que se preocupar com a formação de todos os profissionais, pois ao contrário do que ocorria antes, quando poucos educadores se dedicavam a trabalhar com os alunos ditos especiais, hoje não mais existe esta opção. Todos devem estar preparados já que em qualquer momento de sua trajetória profissional terá que lidar com alunos que apresentam necessidades educacionais especiais.

Com toda certeza, a escola é o melhor lugar para o desenvolvimento de um a educação inclusiva. Representa o principal espaço de socialização, fora do âmbito familiar. Porém, não basta somente inserir os alunos com necessidades especiais neste espaço, é necessário que se tenha estrutura e conhecimento por parte de todos os envolvidos para que promova de fato uma educação inclusiva.

A troca de experiências entre professores e demais profissionais da escola e de outros espaços da comunidade é a chave para a construção de teorias e praticas mais bem sucedidas no campo da inclusão escolar.

Cabe lembrar que o professor sozinho não faz a inclusão. A política sozinha não faz a inclusão. Inclusão se faz junto e para isto tem que ter coragem.

\section{REFERÊNCIAS}

\section{BRASIL. Declaração de Salamanca. UNESCO, 1994. \\ Disponível em: \\ http//:portal.mec.gov.br/seesp/arquivos/pdf/sa lamanca.pdf. Acesso em 01 de novembro de 2010.}

CARVALHO, Rosita Elder. Escola inclusiva: a reorganização do trabalho pedagógico. 2. ed. Porto Alegre: Mediação, 2008. 152 p.

FERREIRA, Aurélio Buarque de Holanda, Aurélio século XXI, o dicionário da língua portuguesa.3.ed. totalmente rev. E ampl. Rio de Janeiro: Nova Fronteira, 1999.2128 p

GARCIA, M. A. Multiprofissionalismo e intervenção educativa: as escolas, os projectos e as equipas. Porto: Edições ASA, 1994.

GLAT, Rosana (Org.). Educação inclusiva: cultura e cotidiano escolar. Rio de Janeiro: 7 Letras, 2007. $210 \mathrm{p}$.

\section{LDB. Lei de Diretrizes e Bases da}

Educação Nacional- Lei no 9.394, de 20 de dezembro de 1996.

Disponível em:

http://portal.mec.gov.br/arquivos/pdf/ldb.pdf. Acesso em 16 de outubro de 2010.

MINAS GERAIS. Secretaria de Estado de Educação. Projeto Incluir: caderno de textos para formação de professores da rede pública 
de Minas Gerais. Belo Horizonte: Secretaria de Estado de Educação, 2006. 111 p. (Livro 2.)

MENDES, E. G. Sobre a definição da área de educação especial. (Mimeo,1995).

ZURRO, A. M.; FERREROX, P.; BAS, C. S. A equipa de cuidados de saúde primários:

manual de cuidados primários, Lisboa:

Farmapress Edições, 1991. 